\section{Simplified methods to inventory the current annual increment of forest standing volume}

\author{
Pasquale Antonio Marziliano ${ }^{(1)}$, Giuliano Menguzzato ${ }^{(1)}$, Angelo \\ Scuderi ${ }^{(1)}$, Piermaria Corona ${ }^{(2)}$
}

The assessment of the current annual increment of forest standing volume (CAI) is a fundamental tool to support forest management and planning. A suitable approach to such an end is to rely on growth and yield models. However, this kind of models are often not available for many countries and/or locations and/or species. Furthermore, they may become obsolete due to potential changes in the environmental and silvicultural conditions. Such shortcomings may be distinctively detrimental in the context of forest inventories. Several methods have been proposed to inventory CAl on one single occasion, i.e., when repeated measurements of standing volume are not available. A wellknown family of methods, still largely exploited in Alpine and Eastern European countries, derives from the estimation of the percentage current annual increment of forest standing volume by the current annual increments of stem diameter and tree height $(\Delta h)$. In this study an experimental comparison of $\Delta h$ assessment by three different approaches is presented with reference to a properly designed case study: (i) $\Delta h$ is measured on felled trees; (ii) $\Delta h$ is estimated by dynamic height curve (i.e., diameter-height-age model); (iii) $\Delta h$ is estimated by conventional height curve (i.e., diameter-height model). Under the examined experimental conditions (a pure forest of silver fir on highly fertile soils in southern Italy, aged around 60 years), both simplified approaches (ii) and (iii) have proven to underestimate height increments, with a larger underestimation by the approach based on the conventional height curve. However, the consequent error in the estimation of percentage current annual increment of forest standing volume has proved to be quite limited (4\% for the approach based on the dynamic height curve and around $9 \%$ for the approach based on the conventional height curve). Hence, such simplified approaches may be rather safely considered for estimating percentage current annual increment of forest standing volume when neither $\Delta h$ is directly detectable on standing trees nor sample trees can be felled, nor an appropriate model to predict $\Delta h$ is available. The $\Delta h$ estimation on the conventional height curve should turn out to be even more suitable in the case of uneven-aged stands, where the position of the height curve remains stationary over time.

Keywords: Forest growth, Percentage current annual increment, Current annual increment of tree height, Schneider's coefficient, Forest management, Forest inventory

\section{Introduction}

The assessment of current annual increment of forest standing volume $(C A I)$ is a fundamental tool to support forest management and planning (Assmann 1970, Davis et al. 2001), in order to quantify the productivity of forest stands, to understand their growth dynamics (at least on a short-term perspective) and to improve the management strategies according to sustainable adaptive approaches.

However, the growth dynamics of a given forest stand is not easy to be reliably assessed on one single occasion, i.e., when repeated measurements of standing volume are not available. A suitable approach to such an end is to rely on growth and yield models (e.g., Vanclay 1994, von Gadow \& Hui
(1) Dipartimento di Gestione dei Sistemi Agrari e Forestali (GESAF), Mediterranean University di Reggio Calabria, Località Feo di Vito, I-89060 Reggio Calabria (Italy); (2) Dipartimento per l'Innovazione nei sistemi Biologici, Agroalimentari e Forestali (DIBAF), University of Tuscia, via San Camillo de Lellis snc, I-01100 Viterbo (Italy).

(a) Pasquale Antonio Marziliano (pasquale.marziliano@unirc.it)

Received: Jul 18, 2012 - Accepted: Oct 16, 2012

Citation: Marziliano PA, Menguzzato G, Scuderi A, Corona P, 2012. Simplified methods to inventory the current annual increment of forest standing volume. iForest 5: 276-282 [online 2012-12-17] URL:

http://www.sisef.it/iforest/contents? id=ifor0635-005

Communicated by: Marco Borghetti

nual increment of the stand is then straightforwardly calculated as (eqn. 1):

$$
C A I_{s t}=\frac{P C A I_{s t} \cdot V_{s t}}{100}
$$

where (eqn. 2):

$$
P C A I_{s t}=\frac{\sum_{j=1}^{m} P C A I_{j} \cdot V_{j}}{\sum_{j=1}^{m} V_{j}}
$$

where $P C A I_{\mathrm{j}}$ is the percentage current annual increment of forest standing volume, referred to the $j$-th dbh (tree stem diameter at breast height) class; $V_{\mathrm{j}}$ is the forest standing volume, referred to the $j$-th dbh class; and $m$ is the number of dbh classes in the stand.

All the approaches applied for estimating $P C A I$ are derived from simplifications of the following general formula referred to individual standing trees (eqn. 3):

$$
P C A I=100 \cdot\left(\frac{2 \Delta d}{d}+\frac{\Delta h}{h}+\frac{\Delta f}{f}\right)
$$

of models are often not available for many countries and/or locations and/or species. Furthermore, they may become obsolete due to eventual changes in the environmental and silvicultural conditions (Weiskittel et al. 2011). Such shortcomings may be distinctively detrimental in the context of forest inventories.

Several methods have been proposed for inventorying $C A I$ on one single occasion. A well-known family of methods, still exploited at a large extent in Alpine and eastern European countries, derives from the estimation of the Percentage Current Annual Increment of the forest standing volume $\left(P C A I_{\mathrm{st}}\right)$. By measuring the forest standing volume of a given stand $\left(V_{\text {st }}\right)$, the current an- where $\Delta d$ is the current annual increment of $\mathrm{dbh} ; d$ is the dbh; $\Delta h$ is the current annual increment of tree height; $h$ is the tree height; $\Delta f$ is the annual variation of tree form factor; $f$ is the tree form factor.

On a short-term perspective, $\Delta f / f$ is negliincrement of forest standing volume of a given dbh class can be estimated by the assessment of $\Delta d_{\mathrm{j}}, \Delta h_{\mathrm{j}}$ and $h_{\mathrm{j}}$ referred to that class (eqn. 4):

$$
P C A I_{j}=100 \cdot\left(\frac{2 \Delta d_{j}}{d_{j}}+\frac{\Delta h_{j}}{h_{j}}\right)
$$
gible so that the percentage current annual 
Usually, $\Delta d$ is measured by tree coring at breast height on a representative sample of trees of various dbh classes, so that a relationship between $\Delta d$ and $d$ can be established, from which $\Delta d_{\mathrm{j}}$ is estimated with reference to the $j$-th dbh class. Tree height is measured on the same sample of trees on which $\Delta d$ is measured or on a larger sample, and a relationship between $h$ and $d$ is established (the so-called height curve, known also as diameter-height model), from which $h_{\mathrm{j}}$ is estimated with reference to the $j$-th dbh class. Theoretically, even $\Delta h$ can be measured on the same sample trees on which $\Delta d$ is measured, but such attribute is hardly detectable on standing trees (e.g., almost impossible to be detected in the case of mature broadleaved trees), so that the felling of the sampled trees should be required in most cases. When felling a representative sample of trees is impossible (as it happens very often), simplified approaches not requiring the direct mensuration of $\Delta h$ are adopted.

A suitable approach to such an end is to rely on general models established to predict $\Delta h$ as a function of easily assessable attributes of standing trees: the models by Stage (1975) and Hasenauer (1999) are relevant examples to this respect. However, as previously stressed for growth and yield models, even these particular models are often not available for many countries and/or locations and/or species.

In order to circumvent the estimation of $\Delta h$, various practical simplifications of the eqn. 4 are adopted under temperate, alpine and Mediterranean conditions. Distinctively, the simplification proposed by Schneider in 1853 (reported by Prodan 1965 and La Marca 2004) is one of the most commonly adopted in central and southern Europe. To provide growth estimates to forest management, under the so called forest inventory by compartments (Corona et al. 2009), parameters in eqn. 4 are combined into the simpler form (Prodan 1965, la Marca 2004 eqn. 5):

$$
P C A I=\frac{K}{n \cdot d}
$$

where $K$ is the Schneider's coefficient and $n$ is the number of tree rings included in the outer centimeter of the core sampled at the breast height.

The parameters $n$ and $d$ can be easily determined by direct measurements in the field. On the other hand, the input of $K$ may become questionable, since the simplicity of the eqn. 5 is more apparent than real. Literature reports the overall range of $K$ values constrained between 400 and 800 , with 400 for old-growth trees and 800 for the youngest ones. In practice, the most frequent $K$ values range between 450 and 650 (Hellrigl $1969,1986)$. However, because of assessment difficulties, it is rather often adopted

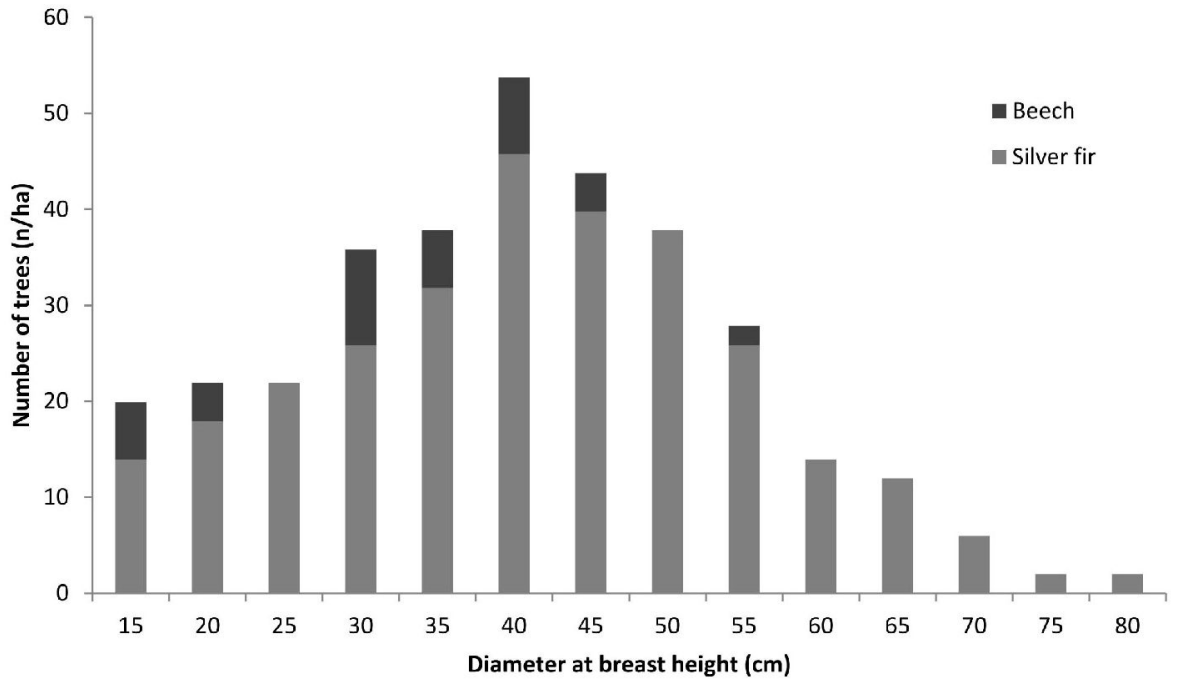

Fig. 1 - Tree dbh distribution in the examined stand.

(e.g., in some Alpine regions) a conventional $K$ value equal to 400 (the so-called K400 criterion, assuming that both $\Delta f / f$ and $\Delta h / h$ are negligible) for all the trees sampled in a given forest, with the obvious underestimation of $P C A I_{\text {st. }}$ On the other hand, assuming that only $\Delta f / f$ is negligible (i.e., the same reasonable assumption underlying the eqn. 4), the following formula, derived by equating eqn. 5 with eqn. 4, can be exploited to objectively establish the $K$ value corresponding to a given dbh class when $\Delta h, h$ and $\Delta d$ referred to that class are known (eqn. 6):

$$
K_{j}=200 \cdot\left(2+\frac{\Delta h_{j}}{h_{j}} \cdot \frac{d_{j}}{\Delta d_{j}}\right)
$$

However, this formula again poses the question of estimating $\Delta h$.

\section{Study aim}

Simplified approaches for an approximate estimation of the annual increment of tree height in a given forest stand can be exploited when direct mensuration is impossible and general prediction models are not available. A suitable approach is based on the difference between the heights assessed on the height curve (i.e., the diameterheight model established for a given forest stand) with reference to two successive dbh classes and the number of years that a tree takes to move from a given dbh class to the next (i.e., the recruitment period, $R$ ) in that stand (eqn. 7):

$$
\Delta h_{j}=\frac{h_{j+1}-h_{j}}{R_{j}}
$$

This approach has been adopted to some extent, e.g., in the Italian National Forest Inventory (IFNI 1988, INFC 2009). However, the reliability of eqn. 7 for estimating $P C A I$ does not seem to be corroborated yet. In the best of our knowledge, besides Marziliano et al. (2011), no other peer-reviewed experimental studies have been devoted to this issue: most probably, results concerning this topic are not published nor are they accessible. Such a knowledge gap has stimulated this research note.

The height curve is established on the basis of the sample trees from the stand of interest. However, it is well known that the more an even-aged forest is mature, the more the height curve is flattened (Pretzsch 2009). In such a case tree heights may vary relatively little with increasing $\mathrm{dbh}$. In the case of mature even-aged stands, this suggests that the estimation of $\Delta h$ through the difference between the heights of two contiguous dbh classes as predicted by the height curve may provide $\Delta h$ values lower than the actual ones. To circumvent this shortcoming, a so called dynamic height curve (known also as diameter-height-age model), based on the height-dbh relationship as a function of stand age, can be established (Pretzsch 2009).

Here we report the results of a comparison of $P C A I_{\mathrm{st}}$ assessment by eqn. 2 and eqn. 4 according to three different approaches for estimating $\Delta h$, applied under a properly designed case study: (i) benchmark approach: $\Delta h$ is measured on felled trees; (ii) dynamic height curve approach: $\Delta h$ is estimated by the eqn. 7 applied with reference to the dynamic height curve (i.e., the diameter-heightage model); (iii) conventional height curve approach: $\Delta h$ is estimated by the eqn. 7 applied with reference to the conventional height curve (i.e., the diameter-height model). For further comparison, $P C A I_{\mathrm{st}}$ is also estimated by the conventional K400 criterion (i.e., eqn. 5 with a $K$ value equal to 400 ). 
Tab. 1 - Descriptive statistics of the attributes measured on the sampled trees. (SD): standard deviation; (SE): standard error.

\begin{tabular}{lcccccc}
\hline \multicolumn{1}{c}{ Attribute } & mean & SD & Skewness & Skewness & \multirow{2}{*}{ Kurtosis } & Kurtosis \\
& & & & SE \\
\hline dbh $(\mathrm{cm})$ & 37.4 & 11.3 & 0.85 & 0.25 & 0.91 & 0.50 \\
current annual increment & 0.60 & 0.12 & 0.37 & 0.25 & -0.61 & 0.50 \\
$\begin{array}{l}\text { of dbh }\left(\mathrm{cm} \mathrm{yr}{ }^{-1}\right) \\
\text { height (m) }\end{array}$ & 26.9 & 3.41 & 0.05 & 0.25 & -0.05 & 0.50 \\
$\begin{array}{l}\text { current annual increment } \\
\text { of height }\left(\mathrm{m} \mathrm{yr}^{-1}\right)\end{array}$ & 0.28 & 0.07 & -0.06 & 0.25 & -0.40 & 0.50 \\
\hline
\end{tabular}

\section{Materials and methods}

\section{Field survey}

The study site is located within a silver fir (Abies alba Mill.) high forest of approximately 850 hectares, located in the Calabrian

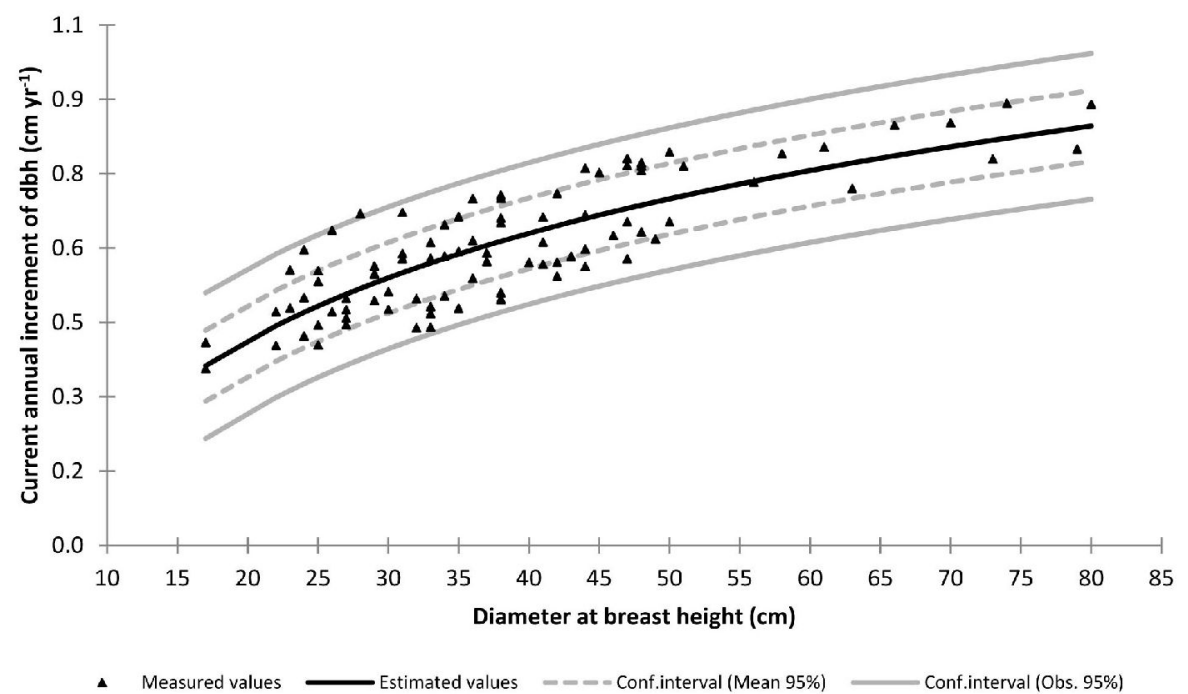

Fig. 2 - Current annual increment of dbh $v s$. dbh from the sampled trees, with the established functional relationship superimposed.

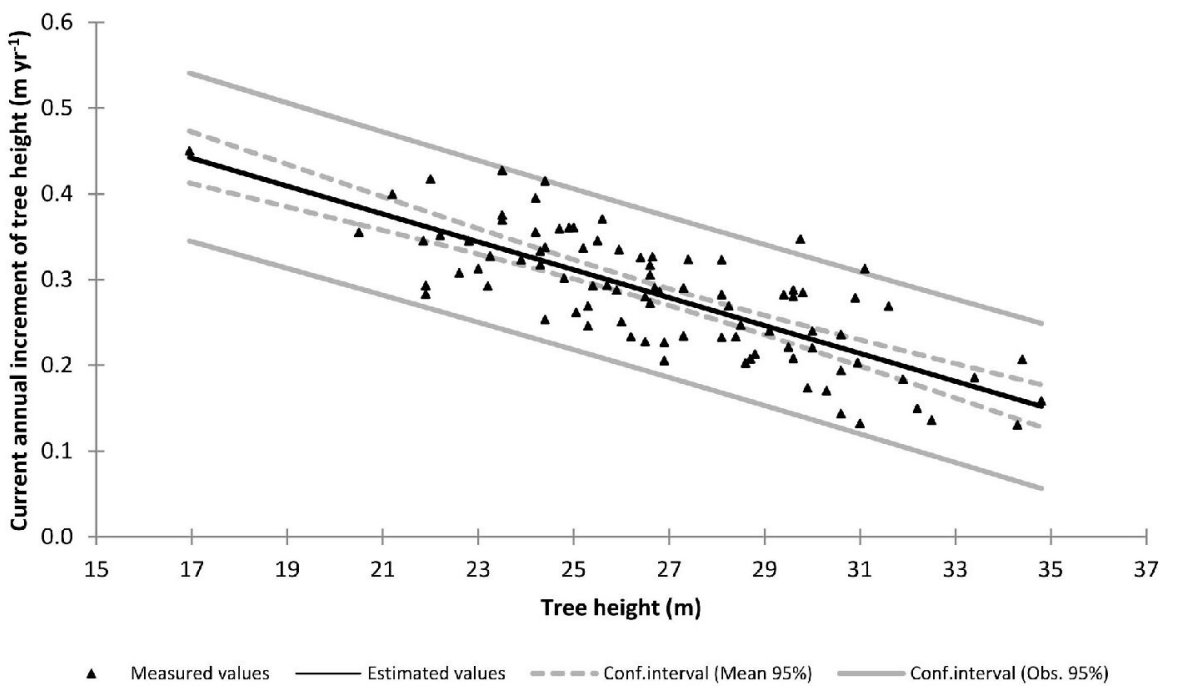

Fig. 3 - Current annual increment of tree height $v s$. tree height from the sampled trees, with the established functional relationship superimposed. $38^{\circ} 32$ '24” $\mathrm{N}$, longitude $16^{\circ} 18^{\prime} 24^{\prime \prime} \mathrm{E}$ ) is on a flat terrain and it is characterized by an evenaged structure including scattered groups of beech trees.

The measurements were carried out in a 0.5 ha plot representative of the average conditions of the stand. The dbh of all the trees with dbh $>12.5 \mathrm{~cm}$ was measured (Fig. 1). Subsequently, 91 trees (i.e., around 54\% of the standing trees) were selected by stratified random sampling, with sample size proportional to the number of trees in each dbh class. An increment core was taken by a Pressler borer at stem breast height on each selected standing tree, on a random direction and perpendicularly to the longitudinal axis of the tree. The total tree height and the height increments corresponding to the last ten years were measured on the same selected trees just after the felling. Tab. 1 summarizes the main descriptive statistics of the measured dendrometrical parameters, all of which show normality of distribution.

\section{Lab analyses and data processing}

Annual stem growth ring count and width measurement (with a precision of $1 / 100 \mathrm{~mm}$ ) were carried out on the last ten rings of each sampled core by the LINTAB system (RinnTec) associated with TSAP software (http://www.rinntech.de/content/view/16/47/ lang,english/). $\Delta d$ was calculated as $2 \cdot \mathrm{r}_{10} / 10$ where $r_{10}$ is the increment of the radius occurred in the last 10 years. The $\Delta d-d$ relationship was then established on the sampled trees, taking care of subtracting the measured $\Delta d$ value (expressed in $\mathrm{cm} \mathrm{yr}^{-1}$ ) to the $d$ value (expressed in $\mathrm{cm}$ ) measured on the same tree. Among various functional forms, the semilogarithmic one proved to be the most suitable (Fig. 2 - eqn. 8):

$$
\Delta \hat{d}=-0.5425+0.3189 \cdot \ln (d)
$$

with $R^{2}=0.67$ and SEE $=0.071 \mathrm{~cm} \mathrm{yr}^{-1}$. The recruitment period, i.e., the number of years that a tree of average size takes to move from a dbh class to the next (according to a dbh class width equal to $5 \mathrm{~cm}$ ), is given by $R_{\mathrm{j}}=$ $5 / \Delta d_{\mathrm{j}}$, where $\Delta d_{\mathrm{j}}$ is the current annual dbh increment predicted by the eqn. 8 for the $j$-th dbh class.

$\Delta h$ was calculated as $\Delta h=l_{10} / 10$, where $l_{10}$ is the stem length corresponding to the height increment in the last 10 years. The $\Delta h-h$ relationship was established on the sampled trees, taking care of subtracting the measured $\Delta h$ value (expressed in $\mathrm{m} \mathrm{yr}^{-1}$ ) to the $h$ value (expressed in $\mathrm{m}$ ) measured on the same tree. Among various functional forms, the linear one proved to be the most suitable (Fig. 3 - eqn. 9):

$$
\Delta \hat{h}=0.7178-0.0163 \cdot h
$$


conventional height curve was established by the scatterplot of the heights $v s$. dbh values measured on the sampled trees. As suggested by Hellrigl (1986), the dynamic height curve was established by the scatterplot of the heights $v s$. dbh values corresponding to the average-size tree predicted for each age class by the local yield table for Abies alba stands, first fertility class (Principe 1974), provided that stand density and mean height of the examined stand was comparable with those reported for this fertility class at the same age. Fig. 4 shows the scatterplot of the height $v s$. dbh values measured in the considered stand, with both the conventional and the dynamic height curves superimposed: as expected, the dynamic curve is much steeper than the conventional one, since it explicitly takes into account height growth dynamics.

$P C A I_{\mathrm{j}}$ was estimated by eqn. 4 for the approaches (i), (ii) and (iii) mentioned in the chapter "Study aim", while it was estimated by eqn. 5 for the application of the K400 criterion (where $n_{\mathrm{j}}=2 / \Delta d_{\mathrm{j}}$ )). For all cases $\Delta d_{\mathrm{j}}$ was obtained by eqn. 8 and $h$ was obtained by the conventional height curve. $\Delta h_{\mathrm{j}}$ was obtained either directly applying eqn. 9 in the case of the benchmark approach or by applying eqn. 7 in the cases of the dynamic and the conventional height curves. The standing volume was estimated by the Italian National Forest Inventory volume models valid for silver fir (Tabacchi et al. 2011).

\section{Results}

At the time of inventory, the average tree age was about 60 years; the number of trees per hectare was 336 ; beech was present with 40 individuals per hectare, i.e., $12 \%$ of the total of trees. The distribution of trees by dbh classes showed a typical bell-shaped pattern, with dbh up to $80 \mathrm{~cm}$ (Fig. 1) and a quadratic mean dbh (qmd) of silver fir around $44 \mathrm{~cm}$. The tree height corresponding to qmd was around $28 \mathrm{~m}$; the wood volume of the trees with $\mathrm{dbh}>12.5 \mathrm{~cm}$ was $651 \mathrm{~m}^{3}$ $\mathrm{ha}^{-1}$, of which $93 \%$ was due to the silver fir.

The examined stand is characterized by $\Delta d$ ranging from 0.36 to $0.41 \mathrm{~cm} \mathrm{yr}^{-1}$ for the smallest dbh class $(15 \mathrm{~cm})$ and from 0.80 to $0.89 \mathrm{~cm} \mathrm{yr}^{-1}$ for the largest one $(80 \mathrm{~cm})$. Correspondingly, the period for a tree of a given dbh class to move onto the next dbh class ranges, on average, from 16 years for the 15$\mathrm{cm}$ dbh class down to 6 years for the $80-\mathrm{cm}$ dbh class. Measured $\Delta h$ ranges from 0.40 to $0.45 \mathrm{~m} \mathrm{yr}^{-1}$ for the smallest dbh classes and from 0.15 to $0.21 \mathrm{~m} \mathrm{yr}^{-1}$ for the largest ones (31-35 m).

Tab. 2 shows the high significance ( $\mathrm{p}<0.01$, according to the paired-sample $t$ test and to the Wilkoxon paired-sample test Zar 1996) of the $\Delta h$ estimation differences between the simplified and the benchmark approaches. Fig. 5 shows the $P C A I_{\mathrm{j}}$ values

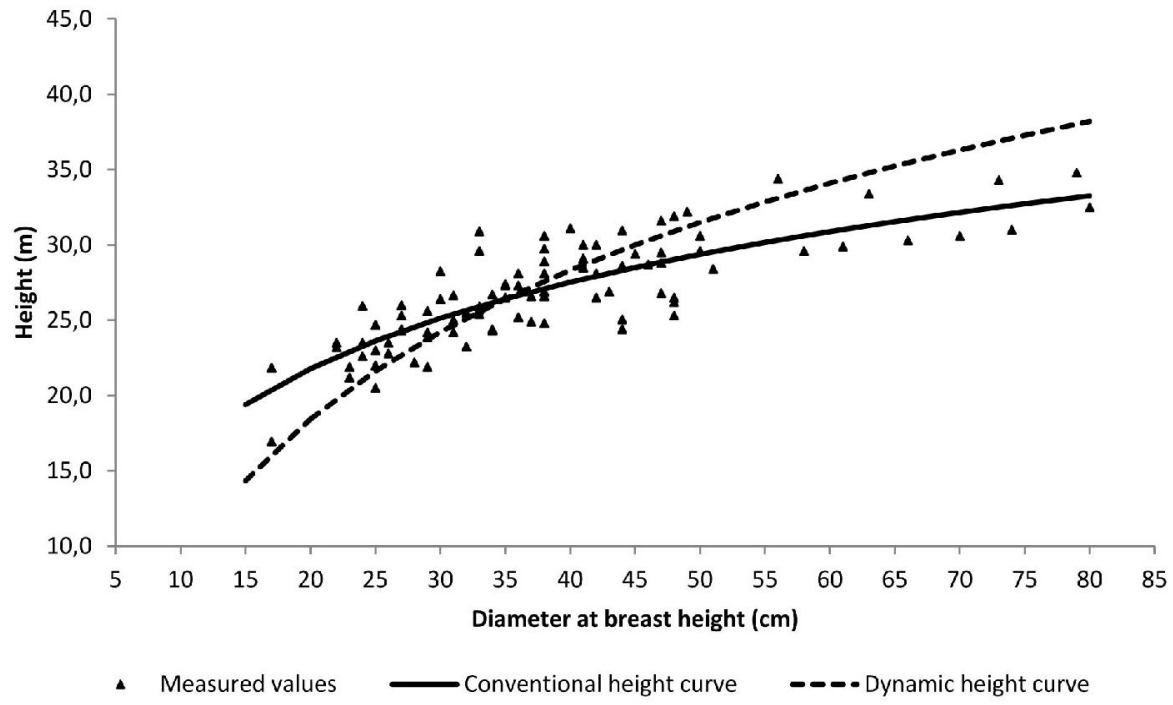

Fig. 4 - Scatter-plot of measured height $v s$. dbh values from the sampled trees, with the conventional and the dynamic height curves superimposed.

estimated for each dbh class by the three compared approaches and by the K400 criterion. As expected, $P C A I_{\mathrm{j}}$ decreases with increasing dbh. Both simplified approaches adopted to assess $\Delta h$ do underestimate $P C A I_{\mathrm{j}}$, for all the dbh classes as per the approach based on the conventional height curve and for the classes below $60-65 \mathrm{~cm}$ as per the approach based on the dynamic height curve. The differences between the simplified approaches and the benchmark approach are larger for the smaller dbh classes and become smaller for the larger with respect to the $15-\mathrm{cm}$ dbh class down to $2.6 \%$ with respect to the $80-\mathrm{cm}$ dbh class for ones. Distinctively, $P C A I_{\mathrm{j}}$ ranges from $7.4 \%$

Tab. 2 - Significance of the $\Delta h$ estimation differences between the simplified and the benchmark approaches, assessed by the paired-sample $t$ test (T) and to the Wilkoxon paired-sample test $(Z)$ for the dbh classes in the examined stand.

\begin{tabular}{lcc}
\hline \multicolumn{1}{c}{ Paired comparison } & $\mathbf{T}$ & $\mathbf{Z}$ \\
\hline $\begin{array}{l}\text { dynamic height curve } \\
\text { approach - benchmark }\end{array}$ & 7.07 & -3.30 \\
$\begin{array}{l}\text { approach } \\
\text { ap } 0.01)\end{array}$ & $(\mathrm{p}<0.01)$ \\
$\begin{array}{l}\text { conventional height } \\
\text { curve approach - } \\
\text { benchmark approach }\end{array}$ & $\begin{array}{c}9.38 \\
(\mathrm{p}<0.01)\end{array}$ & $\begin{array}{c}-3.30 \\
(\mathrm{p}<0.01)\end{array}$ \\
\hline
\end{tabular}

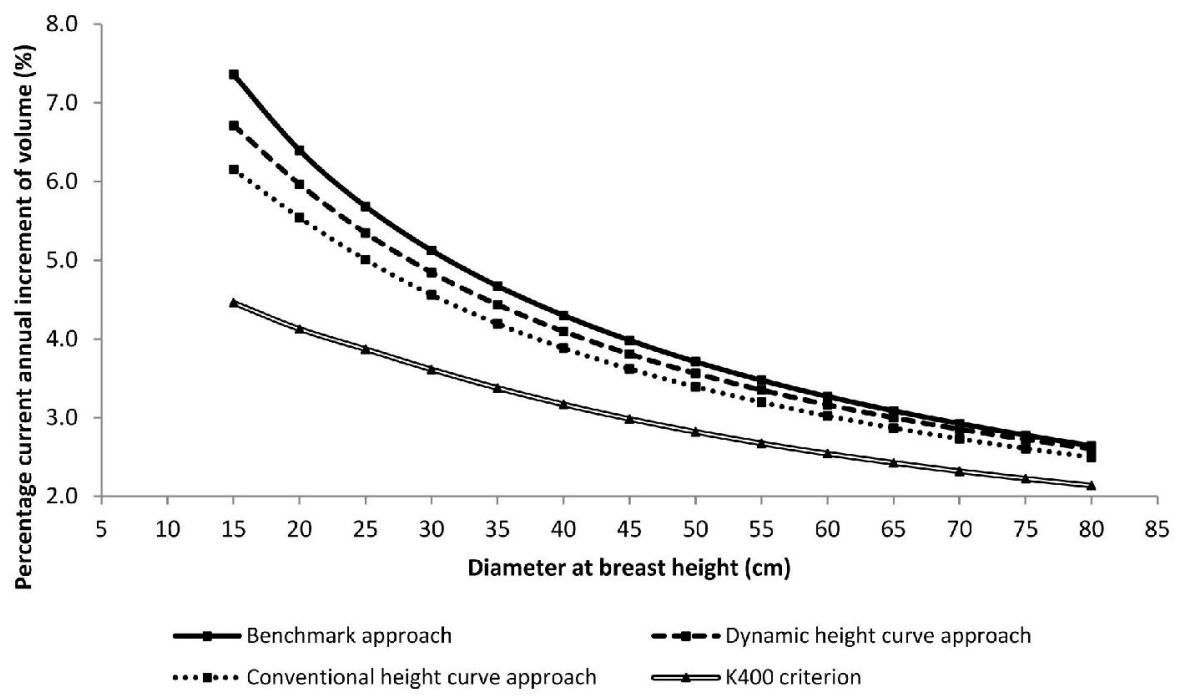

Fig. 5 - Trends of percentage current annual increment of volume calculated in the examined stand according to the three approaches compared for assessing $\Delta h$ and to the K400 criterion. 
Tab. 3 - $C A I$ values estimated for each dbh class in the examined stand by the compared approaches.

\begin{tabular}{|c|c|c|c|c|}
\hline $\begin{array}{l}\text { dbh class } \\
\text { (cm) }\end{array}$ & $\begin{array}{c}\text { Benchmark } \\
\text { approach for } \\
\text { assessing } \Delta h \\
\left(\mathrm{~m}^{3} \mathrm{ha}^{-1} \mathrm{yr}^{-1}\right)\end{array}$ & $\begin{array}{c}\text { Dynamic } \\
\text { height curve } \\
\text { approach for } \\
\text { assessing } \Delta h \\
\left(\mathrm{~m}^{3} \mathrm{ha}^{-1} \mathrm{yr}^{-1}\right)\end{array}$ & $\begin{array}{l}\text { Conventional } \\
\text { height curve } \\
\text { approach for } \\
\text { assessing } \Delta h \\
\left(\mathrm{~m}^{3} \mathrm{ha}^{-1} \mathrm{yr}^{-1}\right)\end{array}$ & $\begin{array}{c}\mathrm{K} 400 \\
\text { criterion } \\
\left(\mathrm{m}^{3} \mathrm{ha}^{-1} \mathrm{yr}^{-1}\right)\end{array}$ \\
\hline 15 & 0.14 & 0.13 & 0.11 & 0.08 \\
\hline 20 & 0.33 & 0.30 & 0.28 & 0.21 \\
\hline 25 & 0.62 & 0.59 & 0.55 & 0.42 \\
\hline 30 & 1.04 & 0.99 & 0.93 & 0.74 \\
\hline 35 & 1.71 & 1.62 & 1.53 & 1.24 \\
\hline 40 & 3.12 & 2.98 & 2.82 & 2.30 \\
\hline 45 & 3.34 & 3.19 & 3.04 & 2.50 \\
\hline 50 & 3.80 & 3.65 & 3.47 & 2.89 \\
\hline 55 & 3.05 & 2.94 & 2.81 & 2.35 \\
\hline 60 & 1.90 & 1.84 & 1.76 & 1.48 \\
\hline 65 & 1.85 & 1.80 & 1.72 & 1.46 \\
\hline 70 & 1.04 & 1.02 & 0.98 & 0.83 \\
\hline 75 & 0.39 & 0.38 & 0.36 & 0.31 \\
\hline 80 & 0.43 & 0.42 & 0.41 & 0.35 \\
\hline
\end{tabular}

the benchmark approach, while it varies, respectively, from $6.7 \%$ to $2.6 \%$ according to the dynamic height curve approach and from $6.2 \%$ to $2.5 \%$ according to the conventional height curve approach. The percentage current annual increment of forest volume at stand level is equal to $3.8 \%$ for the benchmak approach, to $3.6 \%$ for the dynamic height curve approach, and to $3.4 \%$ for the conventional height curve approach. Hence, the dynamic height curve approach gives smaller differences (less than half) than the conventional one as to the benchmark. Distinctively, the $P C A I_{\mathrm{st}}$ assessment by the dynamic height curve approach can be considered fairly accurate. On the contrary, the K400 criterion brings to a relevant underestimation of $P C A I_{\mathrm{st}}(2.7 \%)$.

The $C A I$ values assessed by eqn. 1 range from $22.8 \mathrm{~m}^{3} \mathrm{ha}^{-1} \mathrm{yr}^{-1}$ for the benchmark approach to $21.9 \mathrm{~m}^{3} \mathrm{ha}^{-1} \mathrm{yr}^{-1}$ for the dynamic

Tab. 4 - Schneider's coefficient $K$ obtained from eqn. 6 according to the three different approaches for assessing $\Delta h$.

\begin{tabular}{cccc}
\hline $\begin{array}{c}\text { dbh class } \\
(\mathbf{c m})\end{array}$ & $\begin{array}{c}\text { Benchmark } \\
\text { approach }\end{array}$ & $\begin{array}{c}\text { Dynamic height } \\
\text { curve approach }\end{array}$ & $\begin{array}{c}\text { Conventional } \\
\text { height curve } \\
\text { approach }\end{array}$ \\
\hline 15 & 688 & 628 & 575 \\
20 & 620 & 578 & 537 \\
25 & 587 & 553 & 518 \\
30 & 567 & 537 & 505 \\
35 & 553 & 525 & 497 \\
40 & 543 & 517 & 490 \\
45 & 534 & 511 & 485 \\
50 & 527 & 506 & 481 \\
55 & 520 & 501 & 478 \\
60 & 514 & 498 & 475 \\
65 & 509 & 495 & 473 \\
70 & 504 & 492 & 471 \\
75 & 499 & 490 & 469 \\
80 & 495 & 488 & 467 \\
\hline
\end{tabular}

proaches used to assess $\Delta h$. High $K$ values are characteristics of trees with a high relative height increment and a low relative dbh increment, as it usually happens for the smallest dbh classes within a given stand, while the opposite usually holds for the largest ones: consequently, $K$ tends to decrease with increasing dbh. As a result, $K$ significantly decreases from 688 for the 15 $\mathrm{cm}$ dbh class down to 495 for the $80-\mathrm{cm}$ dbh class (values referred to the benchmark approach for assessing $\triangle h$ ). Similarly to $P C A I_{\mathrm{j}}$, the approach based on the dynamic height curve underestimates the $K_{\mathrm{j}}$ values up to dbh of $75 \mathrm{~cm}$, while the conventional height curve approach underestimates the $K_{\mathrm{j}}$ values for all the dbh classes and provides $K$ values more different from that of the benchmark approach than those provided by the dynamic curve approach. The differences of the estimated $K$ values among the approaches used here to assess $\Delta h$ are higher for the smallest dbh classes and become smaller with an increasing dbh.

height curve approach, to $20.8 \mathrm{~m}^{3} \mathrm{ha}^{-1} \mathrm{yr}^{-1}$ for the conventional height curve approach and to $16.5 \mathrm{~m}^{3} \mathrm{ha}^{-1} \mathrm{yr}^{-1}$ for the K400 approach. As expected, similarly to what observed for the $\Delta h$ estimation differences, even the differences among the $C A I$ values obtained by the three compared approaches and the K400 criterion (Tab. 3) are significant $(\mathrm{p}<0.01)$, according to the paired-sample $t$ test and to the Wilkoxon paired-sample test. The $C A I$ shows its maximum value with reference to the $50-\mathrm{cm}$ dbh class, with a value of $3.8 \mathrm{~m}^{3}$ $\mathrm{ha}^{-1} \mathrm{yr}^{-1}$ for the benchmark approach, a value of $3.6 \mathrm{~m}^{3} \mathrm{ha}^{-1} \mathrm{yr}^{-1}$ for the dynamic height curve approach, a value of $3.5 \mathrm{~m}^{3} \mathrm{ha}^{-1} \mathrm{yr}^{-1}$ for the conventional height curve approach and a value of $2.9 \mathrm{~m}^{3} \mathrm{ha}^{-1} \mathrm{yr}^{-1}$ for the K400 criterion.

Tab. 4 shows the $K$ values obtained from eqn. 6 for each dbh class of the examined stand, according to the three different ap-

\section{Discussion}

In this study, two simplified approaches to assess the current annual height increment within the framework of the estimation of PCAI have been tested in an even-aged stand. Under the examined conditions, both simplified approaches have proven to underestimate height increments, with a larger underestimation by the approach based on the conventional height curve. However, the consequent error in the estimation of PCAI is quite limited ( $4 \%$ for the approach based on the dynamic height curve and around $9 \%$ for the approach based on the conventional height curve), relative to the benchmark approach. Hence, such simplified approaches may be rather safely considered for estimating PCAI when neither $\triangle h$ is measureable on standing trees nor sample trees can be felled nor an appropriate model to predict $\Delta h$ is available.

Theoretically, both the simplified approaches are relatively easy to be implemented. However, the dynamic height curve approach is applicable only when an established diameter-height-age model is available and valid for the stand of interest, or when stands of various ages with composition, site fertility and silvicultural treatment similar to those of the stand of interest are available.

Alternatively, the approach based on the conventional height curve can be applied: in this case, underestimation as broad as $9 \%$ may be expected as concerns the assessment of the PCAI in even-aged stands under conditions like those examined in this study. On the other hand, it can be straightforwardly evidenced that to neglect $\Delta h / h$ in eqn. 4 , as e.g., carried out in the professional practice by adopting the so-called K400 criterion (see 
the chapter "Introduction"), conveys too large underestimation, e.g., an unaffordable $C A I_{\text {st }}$ underestimation of nearly $1 / 3$ in the examined case study. In the light of this, when no other practical tools are available, the $\Delta h$ estimation obtainable from eqn. 7 on the conventional height curve is still an advisable option. Furthermore, this tool should be even more suitable in the case of unevenaged stands, where the position of the height curve remains stationary over time (i.e., the height growth in the individual dbh classes remains almost constant, see Pretzsch 2009).

Further considerations can be drawn from the test carried out. From a general point of view, longitudinal and radial stem growth show different patterns (Sumida et al. 1997): under natural conditions, a decrease of the longitudinal growth with size can be observed for most tree species, while radial growth tends to be constant for long time (Hara et al. 1991). Although age influence cannot be completely excluded, various authors (e.g., Maggs 1964 in Enquist 2003 , Mencuccini et al. 2005, Anfodillo et al. 2006, Petit et al. 2008) have shown that the reduction of height increment is mainly due to functional tree-size constraints: from a practical point of view, small trees tend to have greater relative height increments regardless of age, while large trees tend to have gradually smaller relative ones. Thus, the chronological rule-of-thumb proposed by Müller in 1915 and reported by la Marca (2004), and widely adopted by professionals in practical forest management (at least in Italy and in the Alpine region), by which the tree age is the driver of the relationship between $\Delta h / h$ and $\Delta d / d$, may be misleading. By such a rule, the Schneider's coefficient $K$ is conventionally set equal to around 400 for old trees (i.e., $\Delta h / h=0$ ), to around 600 for mature trees (i.e., $\Delta h / h=\Delta d / d$ ) and to around 800 for young trees (i.e., $\Delta h / h=2$ $\Delta d / d$ ), and analogous $K$ reference values are adopted for assessing PCAI of entire evenaged stands. From a trivial point of view, it might seem obvious to associate size with age (especially as concerns the animals), but this is not invariably true for forest trees (Schweingruber 1996), where old small individuals, and vice-versa trees with huge biomass accumulated in few decades, can be found. Then, it is advisable that $K$ values are correctly assigned in the practice not with reference to the age (i.e., as prescribed by the above mentioned chronological rule-ofthumb), but with reference to the size of the trees. Actually, this suggestion is corroborated by the test presented here, where trees of the same age were characterized by very different $K$ values, according to their dbh class (Tab. 4). Eqn. 6 and the connected approaches for estimating $\Delta h$ are helpful tools for pinpointing the suitable $K$ values.

\section{Conclusion}

As a matter of fact, objective decisions need objective information (Corona et al. 2003). Only a sufficiently accurate assessment of forest growth can effectively support management and planning: a suitable silvicultural treatment cannot be properly devised if stand volume increment is not assessed with enough detail, at least on a shortterm perspective, along with tree density, composition, stand structure and volume. This issue is distinctively relevant under an updated vision of forestry, to move from a strictly ruled forest planning to adaptive management, where reliable and cost-efficient monitoring tools become mandatory (Corona \& Scotti 2011).

Within this framework, the eqns. 2, 4 and 7 are suitable for assessing the percentage current annual increment of forest standing volume within sample plots under practical forest inventory purposes on a single occasion, both on a stand-wise level (forest inventory by compartments) or within assessments at larger scales. The simplicity of such formulas is attractive, though they are characterized by several limitations: for instance, the procedure does not take into account tree mortality. However, it gives reasonable predictions on a short-term perspective, when tree mortality can be neglected, leading to a suitable assessment of the current productivity of the considered forest stands. Obviously, the obtained figures are relative to the stands measured and cannot be extrapolated for long periods or to other stands: in this respect, only proper growth and yield models should be exploited (for reference, e.g. Vanclay 1994, von Gadow \& Hui 1999, Corona et al. 2002, Pretzsch 2009, Weiskittel et al. 2011).

As for eqn. 7, whose previously unknown reliability has been the main motivation of this work, it may be safely applied under conditions like those examined here for quantifying the value of $\Delta h$ when neither this parameter is directly measurable on standing trees nor sample trees can be felled nor appropriate prediction models are available. In the light of this, the effectiveness of such an approach is worth to deserve further investigation under various compositional, structural and silvicultural conditions.

\section{Acknowledgments}

This study was partially developed within the scope of research project "FUME Forest fires under climate, social and economic changes in Europe, the Mediterranean and other fire-affected areas of the world", European Commission FP7-ENV-2009, Grant Agreement Number 243888.

We thank the company "La Foresta s.r.l. di Serra San Bruno" for the willingness shown during the surveys in the field.

We also thank four anonymous reviewers for their helpful suggestions on an earlier draft of this paper.

\section{References}

Anfodillo T, Carraro V, Carrer M, Fior C, Rossi S (2006). Convergent tapering of xylem conduits in different woody species. New Phytologist 169: 279-290. - doi: 10.1111/j.1469-8137.2005 01587.x

Assmann E (1970). The principles of forest yield study. Pergamon Press, Oxford, UK.

Corona P, Marziliano PA, Scotti R (2002). Topdown growth modelling: a prototype for poplar plantations in Italy. Forest Ecology and Management 161: 65-73. - doi: 10.1016/S0378-1127(01) 00481-9

Corona P, Koehl M, Marchetti M (2003). Introduction. In: "Advances in forest inventory for sustainable forest management and biodiversity monitoring" (Corona P, Koehl M, Marchetti M eds). Kluwer, Dordrecht, The Netherlands, pp. 71-85.

Corona P, Fattorini L, Franceschi S (2009). Estimating the volume of forest growing stock using auxiliary information derived from relascope or ocular assessments. Forest Ecology and Management 257: 2108-2114. - doi: 10.1016/j.foreco. 2009.02.017

Corona P, Scotti R (2011). Systemic silviculture, adaptive management and forest monitoring perspectives. L'Italia Forestale e Montana 3: 219224. - doi: 10.4129/ifm.2011.3.05

Davis LS, Johnson KN, Bettinger PS, Howard TE (2001). Forest management: to sustain ecological, economic, and social values ( $4^{\text {th }}$ edn). McGraw-Hill, New York, USA.

Enquist BJ (2003). Cope's rule and the evolution of long-distance transport in vascular plants: allometric scaling, biomass partitioning and optimization. Plant Cell and Environment 26: 151161. - doi: 10.1046/j.1365-3040.2003.00987.x

Hara T, Kimura M, Kikuzawa K (1991). Growth patterns of tree height and stem diameter in populations of Abies Veitchii, A. Mariesii and Betula Ermanii. The Journal of Ecology 79: 1085-1098. - doi: 10.2307/2261100

von Gadow K, Hui G (1999). Modelling forest development. Kluwer Academic Publishers, Dordrecht, The Netherlands.

Hasenauer H (1999). Höhenzuwachsmodelle für die wichtigsten Baumarten Österreichs. Forstwissenschaftliches Centralblatt 118: 14-23. - doi: 10.1007/BF02768970

Hellrigl B (1969). Sul calcolo dell'incremento percentuale degli alberi in piedi. L'Italia Forestale e Montana, XXIV: 187-191.

Hellrigl B (1986). Il rilevamento dendro-crono-auxometrico. In: "Nuove metodologie nella elaborazione dei piani di assestamento dei boschi”. Cap. 13. ISEA, Bologna, Italy, pp. 401714.

IFNI (1988). I I Inventario forestale nazionale (Tabacchi G, TosiV eds). MAF, Roma, Italy. INFC (2009). I caratteri quantitativi 2005 - parte 1 , vers. 2. Inventario nazionale delle foreste e dei serbatoi forestali di carbonio (Gasparini P, De 
Natale F, Di Cosmo L, Gagliano C, Salvadori I, Tabacchi G, Tosi V, eds). MiPAAF - Ispettorato Generale Corpo Forestale dello Stato, CRAMPF, Trento, Italy.

la Marca O (2004). Elementi di dendrometria. II Edizione. Patron Editore, Bologna, Italy.

Marziliano PA, Barreca L, Menguzzato G, Nicolaci A, Pelle L, Scuderi A (2011). Struttura e incrementi in boschi puri e misti di abete e faggio sull'Appennino calabrese. L'Italia Forestale e Montana 66 (1): 55-70. - doi: 10.4129/ifm. 2011.1.05

Mencuccini M, Martinez-Vilalta J, Vanderklein D, Hamid HA, Korakaki E, Lee S, Michiels B (2005). Size-mediated ageing reduces vigour in trees. Ecology Letters 8: 1183-1190. - doi: 10.1111/j.1461-0248.2005.00819.x

Petit G, Anfodillo T, Mencuccini M (2008).

Tapering of xylem conduits and hydraulic limita- tions in sycamore (Acer pseudoplatanus) trees. New Phytologist 177: 653-664. - doi: 10.1111/j. 1469-8137.2007.02291.x

Principe M (1974). Piano economico del patrimonio rustico di proprietà del Comune di Serra San Bruno (Catanzaro). Decennio di applicazione 1974-1983/84. C.F.S. Ispettorato Regionale delle Foreste, Reggio Calabria. Ufficio Assestamento Calabria, Catanzaro, Italy.

Pretzsch H (2009). Forest dynamics, growth and yield. Springer Verlag, Berlin Heidelberg, Germany.

Prodan M (1965). Holzmesslehre. J.D. Sauerländer's Verlag, Frankfurt am Main, Germany.

Schweingruber FH (1996). Tree rings and environment dendroecology. WSL FNP Haupt, Bern, Switzerlands, pp. 609.

Stage AR (1975). Prediction of height increment for models of forest growth. Res. Pap. INT-164,
USDA Forest Service, pp. 20.

Sumida A, Ito H, Isagi Y (1997). Trade-off between height growth and stem diameter growth for an evergreen oak, Quercus glauca, in a mixed hardwood forest. Functional Ecology 11: 300-309. - doi: 10.1046/j.1365-2435.1997. 00085.x

Tabacchi G, Di Cosmo L, Gasparini P (2011). Aboveground tree volume and phytomass prediction equations for forest species in Italy. European Journal of Forest Research 130: 911-934. doi: 10.1007/s10342-011-0481-9

Vanclay JK (1994). Modelling forest growth and yield. CAB International, Wallingford, USA.

Weiskittel AR, Hann DW, Kershaw JA, Vanclay JK (2011). Forest growth and yield modeling. John Wiley \& Sons, Ltd, Chicheste, UK.

Zar JH (1996). Biostatistical analysis (3 ${ }^{\text {rd }}$ edn). Prentice-Hall International, New York, USA. 